\title{
Bacillus thuringiensis: en el manejo del agente de la pudrición blanda de la papa Erwinia carotovora
}

\author{
Diana Daniela Portela-Dussán ${ }^{1}$, Alejandro Chaparro-Giraldo', \\ Silvio Alejandro López-Pazos ${ }^{1,2}$
}

\author{
1. Grupo de Ingeniería Genética de Plantas, Departamento de Biología, \\ Universidad Nacional de Colombia, A.A 14-490, Bogotá D.C., Colombia. \\ 2. Facultad de Ciencias de la Salud, Universidad Colegio Mayor de Cundinamarca, \\ Bogotá D.C., Colombia.
}

Correspondencia: salopez@unicolmayor.edu.co

Recibido: 01/30/2013 Aceptado: 18/03/2013

\begin{abstract}
Resumen
En Colombia el cultivo de papa es el cuarto en importancia en la economía del país, y su producción alcanza las 300 millones de toneladas aproximadamente. Erwinia carotovora es una bacteria Gram negativa, anaeróbica facultativa causante de la pudrición blanda de la papa, puede llegar a generar hasta el $100 \%$ de daño en la cosecha, lo cual ocasiona grandes pérdidas económicas. Se ha establecido que la bacteria Bacillus thuringiensis es capaz de suprimir la virulencia de E. caratovora debido a que produce $\mathrm{N}$-acil-homoserina-lactonasa, una potente enzima que degrada de $\mathrm{N}$-acilhomoserinolactonas, que son indispensables en el mecanismo de quorum-sensing de E. caratovora. Esta circunstancia, puede ser una alternativa importante para el control de la enfermedad de la pudrición blanda de la papa. Considerando lo anterior, en este artículo se describe el proceso que emplea la bacteria Bacillus thuringiensis para inhibir la actividad de E. caratovora.
\end{abstract}

Palabras clave: Bacillus thuringiensis, Erwinia carotovora, pudrición blanda, Quorum-sensing.

\section{Bacillus thuringiensis for the control of the potato soft rot Erwinia carotovora}

\begin{abstract}
In Colombia the potato crop is the fourth in importance in the economy of the country, its production reached 300 million tons. Erwinia carotovora is a Gram-negative bacterium, facultative anaerobic which causes the soft rotting of the potato; it can potentially generate up to $100 \%$ damage in the crop, which causes large economic losses. It has been established that the bacterium Bacillus thuringiensis is able to suppress the virulence of $\mathrm{E}$. caratovora because it produces $\mathrm{N}$-acyl-homoserinelactonasa, a powerful enzyme that degrades of $\mathrm{N}$-acyl-homoserinolactonas, which are indispensable in the quorum-sensing mechanism of E. caratovora. This can be an important alternative for the control of the disease of the soft rotting of the potato. Considering the above, this article describes the process used by the bacterium $B$. thuringiensis to inhibit the activity of E. caratovora.
\end{abstract}

Key words: Bacillus thuringiensis, Erwinia carotovora, Quorum-sensing, potato soft rot. 


\section{Introducción}

La papa es uno de los alimentos básicos de la canasta familiar colombiana, es de gran importancia para el sector agrícola del país ya que se cultiva en más de 250 municipios, Cerca de 170.000 hectáreas, con una producción de 1.9 millones de toneladas por año. Aproximadamente $110.000 \mathrm{fa}-$ milias, equivalente a 500.000 personas, dependen directamente de este producto con una generación de 20 millones de jornales al año. Sin embargo, la estabilidad de su producción se ve afectada por el ataque de plagas y enfermedades que pueden llegar a generar grandes pérdidas económicas, por ello se hace indispensable controlar esta amenaza empleando técnicas eficaces que no afectan el equilibrio ecológico y el medioambiente (1-5). Actualmente se emplean métodos de control biológico empleando microorganismos que son enemigos naturales de estas plagas, tal es el caso de Bacillus thuringiensis $(B t)$ una bacteria entomopatógena que posee actividad sobre insectos-plaga de los órdenes Lepidóptera, Coleóptera y Díptera. $B t$ se destaca por su inclusión paraesporal de constitución proteica, encargada de concederle su capacidad insecticida, compuesta de proteínas Cry y Cyt (6).

Bioquímicamente es catalasa positiva, degrada el almidón, glucógeno y $\mathrm{N}$-acetil colina; es capaz de fermentar la glucosa, fructuosa, trealosa, maltosa y ribosa. Es miembro del reino Eubacteria, familia Bacillaceae y género Bacillus (7-9). Es considerada una bacteria cosmopolita pues se encuentra ampliamente distribuida en el medio ambiente (6, 9), siendo su hábitat natural el suelo. Es de amplio conocimiento la gran variabilidad genética y la capacidad adaptativa de este microorganismo a los diversos ambientes en los que reside. Múltiples investigaciones han demostrado que $B t$ es una potente herramienta que presenta un sinnúmero de actividades gracias a varios tipos proteínas novedosas, codificadas por genes diferentes a los denominados cry de acción insecticida, creando nuevas posibilidades de aplicación sobre varias clases de agentes infecciosos (10). En este documento se presenta la viabilidad de utilizar $B t$ para el control del agente de la pudrición blanda de la papa Erwinia carotovora.

\section{Erwinia caratovora}

Es un bacilo Gram negativo perteneciente a la familia Enterobacteriaceae, anaerobia facultativa, con presencia de flagelo, no formadora de esporas, su tamaño oscila entre 0,5 a 1,0 micrómetros de ancho por 1,0 a 3,0 micrómetros de largo. Su característica principal que lo diferencia del resto de los miembros de su familia, es la capacidad de producir grandes cantidades de enzimas pépticas responsables de la maceración del tejido parenquimatoso de algunas plantas (PCWDE, del inglés plant cell wall degrading enzymes), por medio de un sistema de señalización química autoinductora extracelular denominado quorum sensing, dependiente de la concentración de la población bacteriana $(10,11)$.

Esta bacteria puede sobrevivir en el suelo dependiendo de las condiciones edafoclimáticas, y de las especies o subespecies involucradas. Dentro de este grupo de bacterias fitopatógenas se encuentran especies relacionadas capaces de dañar cualquier tejido de la planta que invaden y tienen una distribución mundial, por lo general se encuentran en climas donde se cultivan plantas sobre las que ejercen su colonización: E. caratovora ssp. caratovora (fitopatógeno de cultivos de clima frío y templado), E. caratovora ssp. atroseptica (presente en zonas templadas), y E. chrysanthemi (zonas templadas y subtropicales) (11). E. caratovora afecta cultivos de zanahoria, apio, pepino, pimiento, nabo y papa (11). La maceración del tejido parenquimatoso por parte de $E$. caratovora depende en gran medida de las condiciones ambientales, pues se ha demostrado que las temperaturas cercanas a $\operatorname{los} 30^{\circ} \mathrm{C}$ favorecen el incremento en la velocidad de la enfermedad, además determina la especie que genera la infección y por otro lado la humedad debido a la saturación del suelo por el exceso de las lluvias o el riego que produce condiciones anaeróbicas favorece el crecimiento de la bacteria $(11,12)$. 


\section{Pudrición blanda de la papa}

La pudrición blanda del tubérculo se caracteriza por la maceración del tejido parenquimatoso, que termina con la pudrición húmeda y granulosa de color blanco o pardo expidiendo mal olor. E. caratovora, el agente causal de esta enfermedad, inicia la infección incorporándose en las lenticelas y avanzando rápidamente hasta el tubérculo, en ciertas ocasiones se puede presentar una infección latente en la cual el tubérculo se encuentra aparentemente sano, pero las bacterias, al presentarse condiciones favorables, infectan el tubérculo, e incluso otros tejidos $(12,13)$. Cuando afecta los tallos de la planta se denomina como pierna negra debido a una coloración oscura (13).

Esta infección se genera debido a que la bacteria produce PCWDEs, o factores de virulencia, como son pectinasas (pectatoliasa, pectinoliasa, peptinometilesterasa y poligalacturonasa), celulasas (CelZ y Y; CeIV y S) y proteasas (aportan aminoácidos para biosíntesis o degradan proteínas asociadas con la resistencia) $(11,14)$, dependientes de oxígeno, niveles de hierro, nitrógeno, temperatura, osmolaridad, fase de crecimiento, regulación por catabolitos, la activación de proteínas Rc asociadas a sistemas de transducción de señales, niveles de productos de degradación (por medio de un sistema de retroalimentación) entre otros.

Uno de los mecanismos más importantes de regulación de PCWDEs es el sistema de quórumsensing donde se observa que, cuando alcanza una densidad critica de la población bacteriana $\left(10^{6}\right.$ cells $/ \mathrm{mL})$, E. carotovora libera una molécula difusible constitutiva denominada $\mathrm{N}$-(3-oxohexanoil)L-homoserinolactona, ó N-acil-homoserinolactonas (AHLs) mediante los genes expI y carl, (homólogos of luxI in Vibrio fischeri, modelo biológico donde se ha caracterizado el sistema quórum-sensing). Las AHLs generan la síntesis de activadores de la transcripción (CarR y ExpR entre otros) de exoenzimas y del antibiótico carbapenem, generando formación de biopelículas, además de servir de autoinductores de los genes expI y $\operatorname{carI}(11,15)$.
Se ha sugerido que la regulación, dependiente de la densidad poblacional de PCWDE, probablemente se debe a un mecanismo para obtener nutrientes y no como mecanismo de evasión de la defensa de la planta (11). Por otro lado, se ha demostrado que este fitopatógeno presenta sistemas de secreción tipo I (secreta proteasas), II (secretor de pectinasas y celulasas) y III involucrados en el reconocimiento del patógeno mediante efectores (como $\mathrm{HrpN}$ and effector DspE/A) que pueden manipular una respuesta no hospedero por parte del vegetal haciendo que este sea susceptible a la infección bacteriana. Así, E. carotovora actúa como un patógeno oportunista epifítico y endofítico, con un periodo de latencia de varios meses $(11,15)$.

\section{Mecanismo de acción de Bt sobre E. caratovora}

Se conoce que las células se comunican entre sí a través de la secreción de moléculas de señalización (AHLs), en muchos casos la comunicación célula a célula es dependiente de la densidad poblacional (mecanismo de quórum-sensing) (11). Debido a que el mecanismo de quórum-sensing controla actividades implicadas en la interacción hospedero-patógeno y competencia microorganismo-microorganismo, se cree que un sistema de regulación génica puede proveer las proteínas necesarias para generar las señales de quórum-sensing con una ventaja competitiva para su adaptación a su medioambiente. Dado que las interacciones microbio-microbio son frecuentes en los ecosistemas naturales, es de esperar que los microorganismos puedan desarrollar diferentes versiones de mecanismos que interfieran este tipo de señales en sus competidores, a fin de obtener ventajas competitivas que le permitan sobrevivir en el hábitat ecológico, lo cual se denomina antagonismo microbiano (15).

De acuerdo con lo anterior, se ha encontrado que algunas bacterias son capaces de desarrollar enzimas degradadoras de AHLs, interfiriendo con la señalización de sus competidores, como se puede evidenciar con la bacteria $B t$, ya que en esta se ha encontrado una enzima denominada AHL-lactonasa 
(AiiA) (Figura 1), que degrada las AHLs hidrolizando el anillo de lactona de estas señales, a lo que se le llama extinción del quórum-sensing (en inglés quórum-quenching), siendo capaz de desarticular la densidad de la población microbiana, inhibiendo la producción de factores de virulencia y por consiguiente la infección (16-18).

Esta enzima es una metaloproteasa con dos sitios de unión para el zinc (posee el motivo H104-XH106XDH109-H169) con evidencia de su necesidad para su actividad catalítica. El zinc 1 está asociado a histidina $(\mathrm{H})$ 104, H106, H109 y H169, mientras que el zinc 2 se relaciona con los residuos H109, H235 y Asp108 (D108 y D191). Este tipo de enzimas no poseen actividad sobre no-acil-lactonas y esteres no cíclicos, pero tienen fuerte actividad hacia AHLs, incluso si hay variación en la naturaleza de la sustitución en el carbono 3 de la cadena acilo. Los grupos amida y keto serían importantes en la interacción enzima-sustrato. La interacción molecular AiiA-AHL iniciaría con un "ataque" hacia un hidrogeno expuesto por los dos iones zinc, con la subsiguiente reacción con el anillo de lactona, con polarización aumentada del enlace carbonilo, el aminoácido tirosina 194 actuaría como un ácido donador de protones. El ataque al núcleo de la molécula AHL se daría mediante un mecanismo de adición-eliminación sobre un hidróxido derivado del solvente, en los grupos carbonilo, con la eliminación de alcohol (19). Las bondades del gen aiia están demostradas en la generación de un cultivo transgénico de Amorphophallus konjac (o simplemente konjac), una planta asiática usada para biomateriales, cultivo que es aquejado por la enfermedad de la pudrición blanda. Los autores consiguieron seis líneas que expresaron el gen en el análisis por Western blot, las cuales fueron resistentes a la infección por E. carotovora (21). Esta podría ser una opción prometedora para los cultivos de papa en Colombia, ya que variedades transgénicas que expresen el gen aiia serían resistentes a la pudrición blanda causada por E. carotovora (Figura 2).

Se ha demostrado, por diferentes estrategias, que cepas de Bt poseen homólogos del gen aiia (8995\%) con versiones de otras especies de Bacillus, por ejemplo la cepa israelensis 4Q7 se manipuló con el fin de determinar su actividad sobre E. carotovora. Este gen aiia fue mutado y evaluado en pruebas de toxicidad en discos de papa inoculados con $E$. carotovora encontrándose que al emplear la cepa silvestre con expresión normal del gen aiia se presentó una alta protección del tubérculo, lo cual fue contratado con la actividad de cepas mutantes para este gen cuya actividad fue menor $(18,20)$.

Por lo anotado anteriormente, y a manera de conclusión, el estudio de genes de $B t$ ha generado nuevas alternativas para aumentar el rango de acción de esta bacteria frente a agentes fitopatógenos, que mejoren la calidad de la producción de sectores agrícolas. Gracias a estos estudios se ha logrado identificar la propiedad de esta bacteria para actuar sobre el mecanismo de quórumsensing de la bacteria E. caratovora, inhibiendo la producción de sus factores de virulencia que llevan a la pudrición blanda de la papa, mediante el gen aiia de $B t$, por lo cual se presume que esta secuencia de ADN puede ser utilizada en estrategias de manejo de esta enfermedad y así disminuir las pérdidas económicas que causa este microorganismo. 

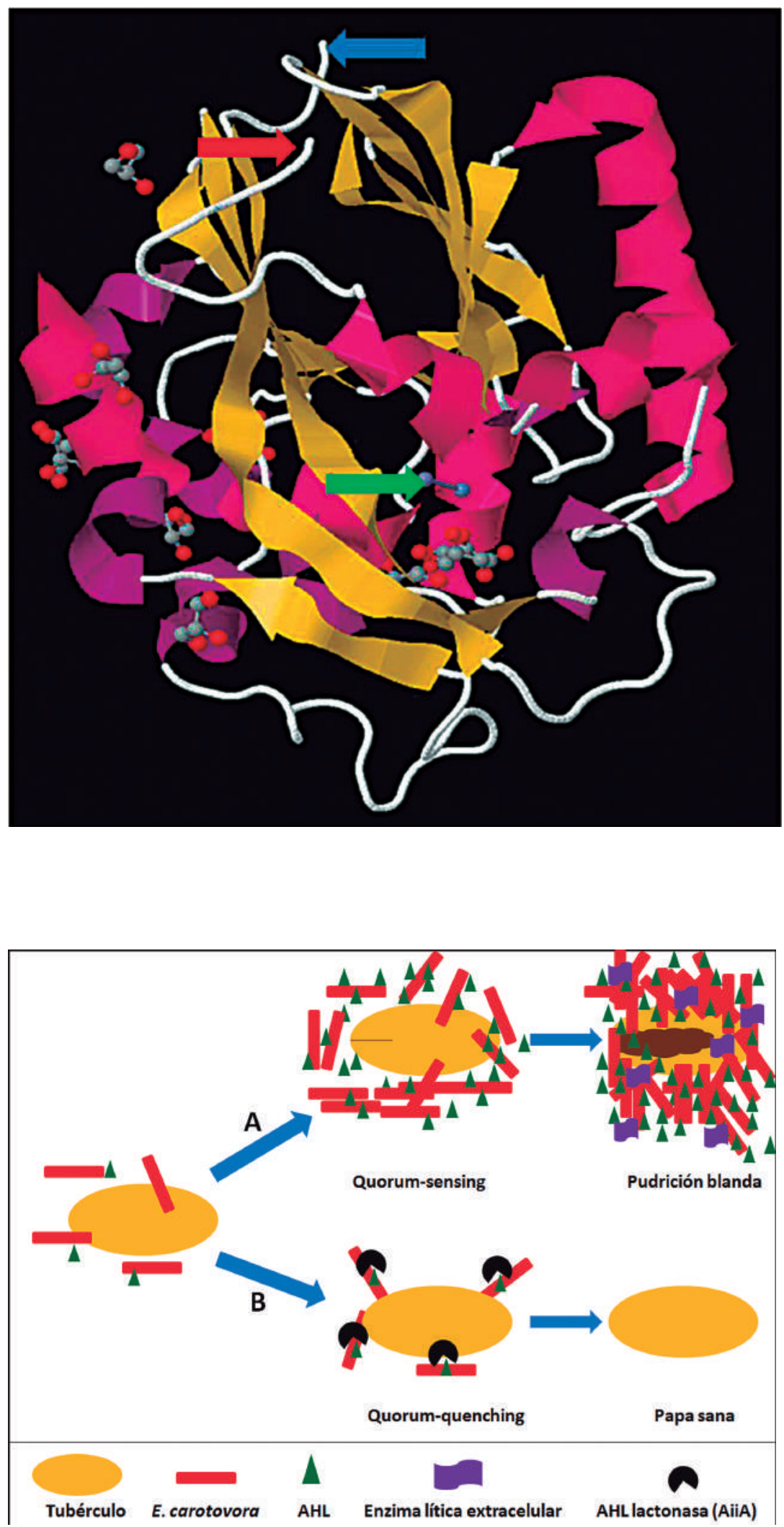

Figura 1. Estructura tridimensional de la enzima AiiA de Bt. En amarillo se presentan las láminas $\beta$ y en rosado las hélices $\alpha$. La flecha verde indica los átomos de zinc en el motivo estructural H104XH106-XDH109-H169. Las flechas azul y roja indican los extremos $\mathrm{N}$-terminal y carboxi-terminal respectivamente. Tomado de Protein Data Bank (http://www. rcsb.org/pdb/home/home.do) ID PDB: 2A7M.

Figura 2. Mecanismo de resistencia a la pudrición blanda de una variedad de papa transgénica portando el gen aiia de Bt. A. Ataque de E. carotovora donde la secreción de AHLs incrementa la densidad celular llevando a la enfermedad. B. Una variedad transgénica expresa la enzima AiiA causando quórum-quenching. Modificado de (22). 


\section{Agradecimientos}

Los autores desean agradecer a Rojo J. por su cooperación en la elaboración de este escrito.

\section{Referencias}

1. Departamento de Agricultura y Protección al ConsumidorOrganización de las Naciones Unidas para la Agricultura y la alimentación FAO. 2007. tesoro enterrado: la papa. Agricultura 21. Recurso en línea: http://www.fao.org/AG/esp/ revista/0611sp1.htm. Revisado 15 de abril 2012.

2. 1. FEDEPAPA - Federación Colombiana de Productores de Papa. 2010. Acuerdo de competitividad de la cadena agroalimentaria de la papa en Colombia. P. 72.

3. Alonso F. El cultivo de la papa, Editorial Mundi-Prensa, Madrid. 1996. pp. 13-29.

4. Moreno D. Problemática del cultivo de la papa en Colombia. Papas Colombianas. Bogotá: Comunicaciones y asociados. 1996; pp 93-102.

5. Espinal C., Martínez H., Pinzón N., Barrios C. 2005. La cadena de la papa en Colombia una mirada global de su estructura y dinámica 1991-2005. Ministerio de Agricultura y Desarrollo Rural. Observatorio de Agrocadenas, Bogotá D.C. Colombia.

6. 1. Pardo-López L., Soberón M., Bravo A. 2013. Bacillus thuringiensis insecticidal three-domain Cry toxins: mode of action, insect resistance and consequences for crop protection. FEMS Microbiol. Rev. 37: 3-22.

7. Porcar M., Juárez-Pérez V. Aislamiento y establecimiento de una colección de Bacillus thuringiensis. En Bacillus thuringiensis en el control biológico. Bravo, A. y Cerón, J. eds. Universidad Nacional de Colombia. Bogotá, Colombia. 2004. pp. 69-100.

8. Bravo A, Cerón J. Ecología y distribución de Bacillus thuringiensis. En Bacillus thuringiensis en el Control Biologico..eds. Universidad Nacional de Colombia. Bogota, Colombia, 2004 pp $49-68$.

9. Ruiz de Escudero I., Ibañez I., Padilla M., Carnero A., Caballero P. Aislamiento y caracterización de nuevas cepas de Bacillus thuringiensis procedentes de tierras canarias. Bol. San. Veg. Plagas. 2004. 30: 703-712.

10. Zhou Y., Choi Y.L., Sun M., Yu Z. Novel roles of Bacillus thuringiensis to control plant diseases. Appl. Microbiol. Biotechnol. 2008. 80: 563-572.

11. Toth I.K., Bell K.S., Holeva M.C., Birch P.R. Soft rot erwiniae: from genes to genomes. Mol. Plant Pathol. 2003. 4: 17-30.

12. Rahman M.M., Ali M.E., Khan A.A., Akanda A.M., Uddin M.K., Hashim U., Abd Hamid S.B. Isolation, characterization, and identification of biological control agent for potato soft rot in bangladesh. Scientific World Journal. 2012: 723293
13. García R. Especies y sub especies de Erwinia, causantes de la pudrición blanda y pierna negra en la papa cultivada en el estado de Merida-Venezuela. Rev. Forest. Venez. 2000. 44: 107-114.

14. Andresen L, Sala E, Kõiv V, Mäe A. A role for the Rcs phosphorelay in regulating expression of plant cell wall degrading enzymes in Pectobacterium carotovorum subsp. carotovorum. Microbiology. 2010. 156: 1323-1334.

15. Toth I.K., Birch P.R.J. Rotting softly and stealthily. Current Opinion in Plant Biology. 2005. 8: 424-429.

16. Dong Y.-H., Zhang X.-F., Xu J.-L., Zhang L.-H. Insecticidal Bacillus thuringiensis Silences Erwinia carotovora Virulence by a New Form of Microbial Antagonism, Signal Interference. Appl. Environ. Microbiol. 2004. 70: 954-960.

17. Zhang L. Fusion of the genes for AHL-lactonase and S-layer protein in Bacillus thuringiensis increases its ability to inhibit soft rot caused by Erwinia carotovora. 2007.

18. Park S-J., Park S-Y., Ryu C-M., Park S-H., Lee J-K. The Role of AiiA, a Quorum-Quenching Enzyme from Bacillus thuringiensis, on the Rhizosphere Competence. J. Microbiol. Biotechnol. 2008. 18: 1518-1521.

19. Liu D., Momb J., Thomas P.W., Moulin A., Petsko G.A., Fast W., Ringe D. 2008. Mechanism of the quorum-quenching lactonase (AiiA) from Bacillus thuringiensis. 1. Product-bound structures. Biochemistry. 47: 7706-7714.

20. Momb J., Wang C., Liu D., Thomas P.W., Petsko G.A., Guo H., Ringe D., Fast W. 2008. Mechanism of the quorum-quenching lactonase (AiiA) from Bacillus thuringiensis. 2. Substrate modeling and active site mutations. Biochemistry. 47: 77157725 .

21. Ban H., Chai X., Lin Y., Zhou Y., Peng D., Zhou Y., Zou Y., Yu Z., Sun M. 2009. Transgenic Amorphophallus konjac expressing synthesized acyl-homoserine lactonase (aiiA) gene exhibit enhanced resistance to soft rot disease. Plant Cell Rep. 28:1847-1855.

22. Barbey C., Crépin A., Bergeau D., Ouchiha A., Mijouin L., Taupin L., Orange N., Feuilloley M., Dufour A., Burini J.F., Latour X. 2013. In Planta Biocontrol of Pectobacterium atrosepticum by Rhodococcus erythropolis Involves Silencing of Pathogen Communication by the Rhodococcal Gamma-Lactone Catabolic Pathway. PLoS One. 8: e66642.

23. Lee S. J., Park S.-Y., Lee J.-J., Yum D.-Y., Koo B.-T., Lee J.-K. 2002. Genes Encoding the N-Acyl Homoserine Lactone-Degrading Enzyme Are Widespread in Many Subspecies of Bacillus thuringiensis. Appl. Environ. Microbiol. 68: 3919-3924. 